\title{
Ovarian activities of the West African dwarf goat (Capra hircus) during oestrus*
}

\author{
M. O. Akusu, A. I. A. Osuagwuh, J. U. Akpokodje and G. N. Egbunike $\dagger$ \\ Departments of Veterinary Surgery \& Reproduction and $\uparrow$ Animal Science, University of Ibadan, \\ Ibadan, Nigeria
}

\begin{abstract}
Summary. Ovarian activity was studied by laparotomy of 9 adult nulliparous goats in which oestrus was synchronized. Ovulation occurred in animals operated on $20-48 \mathrm{~h}$ from the onset of sexual receptivity. There was a mean ovulation rate of 1.57 ova per doe and the right and left ovaries had similar follicular activity in relation to sizes of follicles and ovulations.
\end{abstract}

\section{Introduction}

Reports in the literature indicate breed differences in the duration of oestrus in goats (Van Rensburg, 1971; Jarosz et al., 1971; Smith, 1980), and breed influences have been observed in the interval from the onset of oestrus to ovulation (Harrison, 1948; Sahni \& Roy, 1967; Salama, 1972) and in the number of ova shed by the goat (Shelton, 1960; Lyngset, 1968; Bhattacharyya \& Prasad, 1974). There are very few reports on the reproductive physiology of the West African dwarf goat indigenous to Nigeria (Kirkpatrick \& Akindele, 1974; Akusu \& Egbunike, 1984). J. U. Akopokodje, A. I. A. Osuagwuh and M. O. Akusu (unpublished data) have indirectly studied the ovulation rate of the Maradi goat in Nigeria, but information on the time of ovulation from the onset of oestrus was not determined since the materials for the study were derived from abattoir specimens.

This study was therefore undertaken to provide direct information on the characteristics of ovulation in the West African dwarf goat. Such information is needed before an artificial insemination programme for this breed can be developed.

\section{Materials and Methods}

Animals and treatment. Nine adult nulliparous goats aged 10-12 months and weighing 9.6-14 kg were used. Oestrus was synchronized with PGF- $2 \alpha$ (Dinoprost Tromethamine; Upjohn Company, Kalamazoo, MI, U.S.A.) as described by Akusu \& Egbunike (1984). All animals were housed in roofed concrete-floored pens with low wooden walls in which water and fresh grass were constantly available while corn-based concentrate ration was provided at the rate of $0.5 \mathrm{~kg}$ per head per day. Daily dry-bulb temperatures in the barn ranged from 26 to $33^{\circ} \mathrm{C}$ with the wet-bulb temperature being about $1-2^{\circ} \mathrm{C}$ lower.

All animals were exposed five times daily $(08: 00,12: 00,16: 00,20: 00$ and 24:00 h) to mature aproned males. Assessment of the beginning and duration of standing heat was as described by Akusu \& Egbunike (1984).

\footnotetext{
*Reprint requests to: Professor G. N. Egbunike, Department of Animal Science, University of Ibadan, Ibadan, Nigeria.
} 
Surgical operation. At different times after the start of oestrus, the animals were sedated with acepromazine $(0 \cdot 1 \mathrm{mg} / \mathrm{kg}$ body weight) supplemented with local infiltration of the operation site with xylocaine. The right and left ovaries were exteriorized through a ventral midline incision and assessed according to the method of Rao \& Bhattacharyya (1980).

Follicles $\geqslant 1 \mathrm{~mm}$ in diameter were categorized as very small $(1-1.9 \mathrm{~mm})$, small $(2-2.9 \mathrm{~mm})$, medium $(3-3.9 \mathrm{~mm})$, large $(4-4.9 \mathrm{~mm})$ and very large $(\geqslant 5 \mathrm{~mm})$ in diameter. The occurrence of ovulated follicles in each ovary was also noted.

Data were subjected to $\chi^{2}$ and Student's $t$ tests for the establishment of significance (Snedecor \& Cochran, 1956).

\section{Results}

The operation was successful in all animals and there was no adverse effect on the subsequent reproductive performance of the animals. However, slight ventral hernia anterior to the mammary glands was observed in 2 animals during subsequent pregnancy.

Table 1. Distribution of ovarian follicles $(\geqslant 1 \mathrm{~mm}$ diameter) and ovulated follicles during oestrus in West African dwarf goats

\begin{tabular}{cccccccc}
\hline $\begin{array}{c}\text { Duration of } \\
\text { oestrus (h) } \\
\text { at operation }\end{array}$ & $\begin{array}{c}\text { No. of } \\
\text { animals }\end{array}$ & \multicolumn{5}{c}{ Diameter (mm) of follicles } & Ovulated \\
\cline { 3 - 7 } & $1-1 \cdot 9$ & $2-2 \cdot 9$ & $3-3 \cdot 9$ & $4.4 \cdot 9$ & $\geqslant 5$ & follicles \\
\hline 10 & 1 & - & - & - & 1 & - & - \\
20 & 1 & 3 & 4 & - & 2 & 1 & 1 \\
24 & 3 & 7 & 9 & 6 & 1 & 1 & 3 \\
26 & 1 & 2 & 2 & 3 & 1 & - & 3 \\
30 & 1 & - & 1 & 1 & 1 & - & 1 \\
48 & 2 & 4 & 12 & 11 & 2 & - & 3 \\
Total & 9 & $16^{\text {bc }}$ & $28^{\text {ab }}$ & $21^{\text {a,b }}$ & $8^{\text {c }}$ & $2^{\text {cd }}$ & 11 \\
\hline
\end{tabular}

Values with different superscript numbers are statistically significantly different $(P<0.05)$.

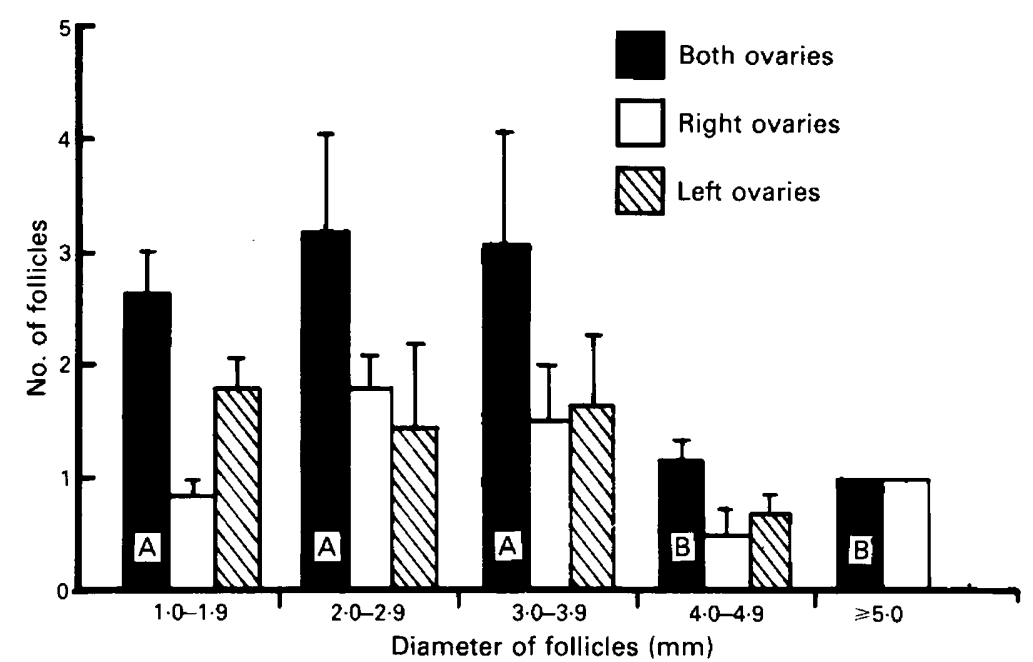

Fig. 1. Variations in the distribution of follicles in different stages of development in the ovaries of 9 West African dwarf goats. Columns bearing different letters differ significantly $(P<0.05)$. Values are means \pm s.e.m. 
Ovulation was not observed in 2 of the animals (operation at 10 and $24 \mathrm{~h}$ after the onset of oestrus). A total of 11 ovulation points (6 right ovary, 5 left ovary: $P>0.05$ ) were noticed in the remaining animals, giving an ovulation rate of 1.57 ova per ovulated animal. Ovulation was observed in most of the animals operated on between 20 and $48 \mathrm{~h}$ after the onset of oestrus (Table 1).

Of the 75 follicles $\geqslant 1 \mathrm{~mm}$ in diameter observed in the ovaries (Fig. 1), $36(48 \%)$ were in the right and $39(52 \%)$ in the left ovary $(P>0.05)$. The very small, small and medium follicles were similar in their frequencies of occurrence in the ovaries. However, the small and medium follicles were more prevalent $(P<0.01)$ than the large and very large follicles which occurred at similar frequencies. A similar trend was recorded for the right and left ovaries.

\section{Discussion}

The mean ovulation rate of 1.57 observed in this study was similar to that reported for the same breed for the number of kids born per female (Akusu \& Egbunike, 1984) and for the Maradi goat ( $1.55 \mathrm{CL} /$ pregnancy) in Nigeria (unpublished data) and the Norwegian goat $(1.6 \mathrm{CL} /$ oestrus: Lyngset, 1968). Values for the Angora (1.2 CL/oestrus: Shelton, 1960) and Barbari (1.4 CL/oestrus: Bhattacharyya \& Prasad, 1974) breeds of goat were lower while those for the Nubian (3.1 CL/ oestrus: Camp et al., 1983) and the Black Bengal (4 CL/oestrus: Rao \& Bhattacharyya, 1980) are higher.

There is great variation on the interval from the beginning of oestrus to ovulation in goats. Nalbandov (1964) and Smith (1980) reported a range of 9-19 h and 12-36 h, respectively, while Salama (1972) and Rao \& Bhattacharyya (1980) reported $27 \mathrm{~h}$ and 32-48 h for Egyptian and Black Bengal goats, respectively. The West African dwarf goat therefore appears to be intermediate between early and late ovulating breeds of goats. Although fertility trials were not conducted, it is suggested that artificial insemination in the West African dwarf goat could be done early in the period of sexual receptivity (Corteel, 1981).

Our observations showed that the right and left ovaries respond similarly in relation to follicular activity, as reported by Rao \& Bhattacharyya (1980) for a polytocous breed of goats. However, Achutankutty \& Raja (1971) and Camp et al. (1983) found greater activity in the right than in the left ovaries of monotocous breeds of goats.

We thank the Upjohn Company for the donation of the PGF-2 $\alpha$.

\section{References}

Achutankutty, A. \& Raja, C.K.S.U. (1971) Studies on the incidence of early embryonic loss in goats based on abattoir specimen. Kerala Vet. J. 2, 13-18.

Akusu, M.O. \& Egbunike, G.N. (1984) Fertility of the West African dwarf goat in its native environment following prostaglandin $F_{2}$-alpha induced estrus. Vet. Quarterly 6, 173-176.

Bhattacharyya, N.K. \& Prasad, S.P. (1974) Ovulation characteristics in nullipara Barbari nannies. Proc. 26th Int. Congr. Physiol. Sci. New Delhi II, 392, Abstr.

Camp, J.C., Wildt, D.E., Howard, P.K., Stuart, L.D. \& Chakraborty, P.K. (1983) Ovarian activity during normal and abnormal length estrous cycles in the goat. Biol. Reprod. 28, 673-681.

Corteel, J.M. (1981). Collection, processing and A.I. of goat semen. In Goat Production, pp. 171-191. Ed. C. Gall. Academic Press, London.

Harrison, R.J. (1948) The changes occurring in the ovary of the goat during the oestrous cycle and in early pregnancy. $J$. Anat. 82, 21-48.

Jarosz, S.J., Deans, R.J. \& Dukelow, W.R. (1971) The reproductive cycle of the African Pygmy and Toggenburg goat. J. Reprod. Fert. 24, 119-123.

Kirkpatrick, R.L. \& Akindele, Z.T. (1974) Reproduction in West African dwarf goats. J. Anim. Sci. 39, 143, Abstr.

Lyngset, O. (1968) Studies on reproduction in the goat. III, The functional activity of the ovaries of the goat. Acta vet. scand. 9, 268-276.

Nalbandov, A.V. (1964) Reproductive Physiology, 2nd edn. W. H. Freeman and Co., San Francisco. 
Rao, V.H. \& Bhattacharyya, N.K. (1980) Ovulation in Black Bengal goats. $J$. Reprod. Fert. 58, 67-69.

Sahni, K.L. \& Roy, A. (1967) A study on the sexual activity of the Barbari goat (Capra hircus) and conception rate through A.I. Ind. J. vet. Sci. 37, 269-276.

Salama, A. (1972) Ovarian changes in goats during oestrus. Ind. J. Anim. Sci. 42, 436 438.

Shelton, M. (1960) A comparison of the ovulation rate at first 3 heat periods of Angora does. J. Anim. Sci. 19, 1227, Abstr.
Smith, M.C. (1980) Caprine reproduction. In Current Therapy in Theriogenology, pp. 971-1004. Ed. D. A. Morrow. W. B. Saunders Company, Philadelphia.

Snedecor, G.W. \& Cochran, W.G. (1956) Statistical Methods, 5 th edn. Iowa State University Press, Ames.

Van Rensburg, S.J. (1971) Reproductive physiology and endocrinology of normal and habitually aborting Angora goats. Onderstepoort J. vet. Res. 38, 1-62.

Received 7 February 1986 